\title{
EL DECORO DE LOS REYES CON LOS BUEYES EN EL TEATRO DE LOPE DE VEGA*
}

Supuestamente, unos conocidos versos del Arte nuevo en los que Lope advierte que "lo trágico y lo cómico mezclado,/ y Terencio con Séneca, aunque sea/como otro Minotauro de Pasife,/ harán grave una parte, otra ridicula", sancionan la hibridación tragicómica que caracteriza a la "comedia nueva". Sin embargo, la referencia al Minotauro es, en medida significativa, una broma intertextual que recuerda el prólogo de Los amantes de Rey de Artieda, quien ya protestaba en 1581 sobre los preceptos del decoro cuando advertía que "para hablar de príncipes y reyes / . . miren los que ordenaron esas leyes, / que sacar al teatro un Minotauro,/ fue mandarnos tratar con semibueyes" (las referencias bibliográficas se hallarán infra, nota 14).

Mi propuesta es la siguiente: el decoro de los reyes se aviene al trato con los bueyes en la coyuntura populista del desarrollo de la comedia nueva; y en particular, el trato con los bueyes en las comedias de Lope de Vega se acoge a la poetización de un legado agrícola que, posiblemente, mitigaría los escrúpulos por el decoro. Con el propósito de medir el alcance de estas alusiones bovinas sobre la calidad principal, tanto del Minotauro como de Pasife, inicié una pesquisa documental que he relegado sustancialmente al embarazo de las notas y de las referencias bibliográficas. Por ejemplo, entre los testimonios que pude registrar, se advierte una premática del último tranco de El diablo cojuelo:

... que ningún príncipe en ellas se finja hortelano por ninguna infanta, $y$ que a las de León se les vuelva su honra con chirimías, por los testimonios que les han levantado; que los lacayos graciosos no se entremetan con las personas reales si no es en el campo o en las calles de noche; que para querer dormirse sin qué ni para qué no se diga: "Sueño me toma", ni otros versos por el consonante, como decir a rey, "porque es justísima ley"...

* Ponencia leida en el VIII Congreso de la Asociación Internacional de Hispanistas celebrado en Brown University, Providence, Rhode Island, agosto 22-27, 1983.

${ }^{1}$ Luis Velez de Guevara, El diablo cojuelo, en La novela picaresca española, ed. Ángel Valbuena Prat, Aguilar, Madrid, 1946, p. 1675. 
Este pasaje resume, a manera de epígrafe, los principales testimonios sobre el decoro de los reyes que he recogido. Vélez ironiza unos clisés dramáticos que eran muy conocidos en suépoca, aunque la consonancia del rey también solía vincularse con otra rima ocasional que lo asociaba al buey en muchas comedias en las que los príncipes se enamoraban en la montaña, o en aquellas en las que una infanta - frecuentemente una infanta de León-- se escondía en un traje de labradora. Solamente entre las comedias auténticas de Lope de Vega, Noël Salomon ha registrado ochenta en las que las huidizas infantas se ocultan en la aldea ${ }^{2}$, y todo estudiante de Lope recuerda aquellas comedias en las que los reyes o los grandes se pierden durante una cacería, en una batalla, o, simplemente, andan de paso por el monte para acabar enamorándose de alguna labradora que, en algunas ocasiones, resulta ser la misma perseguida señora que figuraba en el primer acto.

Este típico predicamento cómico avala unos improperios que Cristóbal Suárez de Figueroa señala en la Plaza universal: "Allí se pierde el respeto á los Príncipes y el decoro á las reinas, haciéndolas en todo libres y en nada continentes, con grande escándalo de virtuosos oídos" 3 . He registrado este "grande escándalo" en muchos otros textos. Por ejemplo, en uno de los anónimos Diálogos de las comedias (que Cotarelo fecha en 1620), un Teólogo acusa:

Ver allí... tenida por dichosa la atrevida y por grande aventura la de aquella que por ser liviana vino a casarse con el Príncipe, y la otra que salió vestida de hombre de casa de su padre y tuvo tales y tales aventuras por donde conseguir casamientos de Príncipes..."

Posteriormente en el “Diálogo Quinto" el mismo Teólogo resume los enredos típicos de comedia a los que correspondería este tipo de acusaciones: "Fuera de esto son semejantes en todas, que a pocas tretas se alcanzan y se ve a dó van a parar... ya el rey que se perdió en la caza y topó una pastora á la cual buscaba; ya de la reina que se aficcionó al criado que vio desenvuelto..." 5

Todos estos escabrosos lances son recogidos en tres versos contundentes de una sátira de mediados del siglo xvn: "Aquí estupran la

\footnotetext{
Nö̈l Salomon, Recherches sur le theme paysan dans la "comedia" au temps de Lope de Vega, Institut d'Études lbérique et Ibéroaméricaines de l'Université de Bordeaux, Bordeaux, 1965, pp. 468-469.

${ }^{3}$ Cristóbal Suárez de Figueroa, Plaza universal de todas ciencias y artes(1615), en Preceptiva dramática española del Renacimiento y el Barroco, eds. Federico Sánchez Escribano y Alberto Porqueras Mayo, 2a ed., Gredos, Madrid, 1972, p. 175.

${ }^{4}$ Diálogos de las comedias (1620), en Bibliografia de las controversias sobre la licitud del teatro en España, ed. Emilio Cotarelo y Mori, Est. Tip. de $R A B M, 1904, \mathrm{pp}$. 213-214

5 lbid., p. 225.
} 
reina, allí la infanta,/ y al rey más cuerdo vuelven sordo y mudo,/ y pecadora a la mujer más santa" .

Sin duda, fueron los jesuítas los que mantuvieron el embate iniciado por el padre Mariana en época de Felipe II en el año emblemático de 1598. Un ejemplo ilustrativo de la tenacidad crítica de los jesuitas es la reacción del padre Agustín de Herrera de la Compañia de Jesús a la defensa de Calderón que prosperaba gracias a algunos apologistas como fray Manuel Guerra. De nuevo, el jesuíta repite los mismos clisés morales: "Infantes y Princesas tampoco faltan; y aun la Majestad real de algunas reinas y emperatrices [que] se introducen en el teatro, no sólo apasionadas, sino fáciles" 7 . Otro jesuita, el padre Ignacio de Camargo - contra quien se exasperó en tantas ocasiones Bances Candamo--, vuelve a las "liviandades de mugeres de punto, y muchas veces de princesas, que después de algunas esquiveces afectadas se rinden últimamente á la porfía a morosa de sus galanes... y, lo que es peor... mugeres mozas y hermosas vestidas como reinas y princesas... ${ }^{8}$ Sin embargo, el Discurso del padre Camargo de 1689 mereció la inmediata respuesta crítica de Bances Candamo en ese mismoaño9 Por estas fechas, ya Bances pudo clasificar el género de las llamadas comedias "de fábrica". Expresa:

[El argumento]... suele ser una competencia por una princesa entre personas reales, con aquel majestuoso decoro que conviene a los personajes que se introducen, mayormente si son reyes o reinas... lleva el poeta gran cuidado en poner decorosa la alusión, venerando por imágenes aun las sombras de lo que se puede llamar real. Y no sé cierto adónde ha visto el padre Camargo comedia de sus tiempos en que estén las princesas fáciles y livianas. Con ingenuidad confieso que no he visto ninguna, ni sé cuál sea ${ }^{10}$.

- Sátiras contra las comedias, las representaciones y los actores ( 1646 y 1649), ibid., p. 546.

Agustin de Herrera, Discurso teológico y político sobre la apología de las comedias... (1682), ibid., p. 356.

${ }^{8}$ Ignacio de Camargo, Discurso teológico sobre los theatros y'comedias de este siglo (1689), ibid., p. 125. Los reparos al vestido, y la práctica de que una actriz represente lo mismo un papel de reina que otro de ramera son muy frecuentes a partir de la crítica seminal del padre Mariana (De los espectaculos, 1598). Otro jesuita, el padre lgnacio de Guzmán expresa en Bienes de el honesto trabajo y daños de la ociosidad... (1613), ibid, p. 349: "Y el mayor (daño) que en esta materia hay en salir á representar y á tañer y cantar y bailar una muger compuesta, afeitada y afectada, lasciva y desenvuelta y de buena gracia y buen parecer... canta, baila y representa y $a$ una reina, ya una ramera". (El subrayado es mío).

Francisco Antonio de Bances Candamo, Teatro de los teatros (1689 y 1690), en Preceptiva..., pp. 345-346, admite, sin embargo, que "los a rgumentos de Lope, ni son todos decentes ni honestos... A hí se hallarán Los donaires de Matico donde está una mujer disfrazada [una Infanta de León] sirviendo de paje a su galán con bien poca decencia en sus acciones y dichos".

10 Ibid., p. 349. 
La protesta de Bances parece estar justificada; sobre tod o cuando él redacta alrededor de 1690, después de la muerte de Lope de Vega; y de ser válida la hipótesis sobre la recurrencia de una observancia del decoro cada vez más rigurosa a medida que avanzaba el siglo Xvir ${ }^{11}$, resulta, entonces, más aceptable la perplejidad y la irritación de Bances con el padre Camargo. Lo cierto es que en su primera época (es decir en las comedias anteriores a 1604) Lope aventuró más allá de lo debido algunos amoríos en la montaña alterando la jerarquía escénica y el orden tradicional de las relaciones de los personajes ${ }^{12}$. El comercio libre entre pastores, labradores y vaqueros con las infantas propició intrigas de escandalosas componendas y de enredos furtivos. A manera de ejemplo, recuerdo una comedia en la que el conde de Saldaña se hacía pasar por el vaquero Antón (El vaquero de Moraña), a causa de sus amoríos con una infanta de León. La aduzco de entrada porque, además de ilustrar la intriga típica de este género de comedias, el conde vaquero expresa aforísticamente la componenda sobre el decoro que nos ocupa: "A quien anda tras los bueyes/ de esta oculta serranía/ entra mal la cortesía/ de las cortes de los reyes" 13 .

En resumen, el contubernio de los reyes con los bueyes rima la falta de respeto al decoro que, de acuerdo con algunos, se le debía a los reyes en la escena; sobre todo, cuando algunas infantas de León se refugian en los montes. Esta controvertible situación ilustra, a mi juicio, una fundamental coyuntura para entender el desarrollo de los modos libres de la comedia nueva al embate de las diatribas de algunos moralistas y

1 DUNCAN MolR, "The classical tradition in Spanish dramatic theory and practice in the seventeenth century", en Classical drama and its influence. Essays presented to $H$. D. F. Kitto, ed. M. J. Anderson, Metheun, London, 1965, pp. 208-209.

12 Expresa el cura en la primera parte del Quijote: "no han llegado todas, como han llegado algunas, al punto de la perfección que requieren. Otros las componen tan sin mirar lo que hacen, que después de representadas tienen necesidad los recitantes de huirse y ausentarse... por haber representado cosas en perjuicio de algunos reyes y en deshonra de algunos linajes". (El subrayado es mío). Cito de Miguel de Cervantes SaAvedra, Don Quijote de la Mancha, ed. Martín de Riquer, Las Americas Publishing, New York, 1958, p. 488.

${ }_{13}$ El vaquero de Moraña, Acad, VII, 580a, ver, además, El testimonio vengado, Acad, VIl, 6lla: "Bien sé yo que estas abarcas,/ Vezadas a andar tras bueyes,/ siguen mal lo que es de reyes,/ de príncipes y monarcas". Las referencias a las comedias de Lope se harán de acuerdo con Obras de Lope de Vega, ed. Marcelino Menéndez Pelayo, 15 vols., Real Academia Española, Madrid, 1890-1913, que abreviaremos Acad, seguida del volumen correspondiente, la página y la columna citada. También se utilizará Obras de Lope de Vega (nueva serie), ed. Emilio Cotarelo y Mori et al., 13 vols., Real Academia Española, Madrid, 1916-1930, con la abreviación AcadNseguida de los datos correspondientes. Este género de comedias lo engrosan, por ejemplo, Los Benavides, Acad, VII, Los donaires de Matico, AcadN, IV, Los Prados de León, Acad, VIl, El postrer godo de España, Acad, VIl, El testimonio vengado, Acad, VII, El vaquero de Moraña, Acad, VII y muchas otras. Esta lista no es más que una muestra de comedias anteriores a 1604. Falta todavía un estudio temático y cronológico completo que un buen equipo de investigadores podría acelerar en algún futuro. 
preceptistas de la época. Ya advertía Juan de la Cueva en el Ejemplar poético: "Que en cualquier comedia hay reyes,/y entre los reyes el sayal grosero/ con la misma igualdad que entre los bueyes" ${ }^{14}$. De seguro, fue Juan de la Cueva el primero en atreverse a faltarle el respeto al decoro; sobre todo al del Prudente Felipe. Al menos el mismo poeta así lo reconoce: "A mí me culpan de que fui el primero/ que reyes y deidades di al tablado,/ de las comedias traspasando el fuero"15, y Agustín de Rojas lo confïma: "Fue el autor primero desto/ el noble Juan de la Cueva;/ hizo del padre tirano,/ como sabéis, dos comedias" 16 .

¿Pero a qué padres tiranos se refiere Rojas? Sin duda, la perspicacia de algunos los remitirá a la leyenda negra fillipina; a las veladas alusiones sobre el príncipe Carlos; a la figura del rey don Sebastián y a la guerra de la sucesión portuguesa. Sólo nos basta un repaso atento del Príncipe tirano, cuya trama alberga alusiones comparables a su momento histórico. Los estudios que conozco sobre estas tangencias históricas son muy convincentes ${ }^{17}$. Sin duda, la década de $1580 \mathrm{con-}$ centra el auge de las traged ias sobre los monarcas tiranos en la escena: La Alejandra de Lupercio Leonardo de Argensola, El principe tirano, de Juan de la Cueva, y alguna que otra pieza anónima conocida como la del Tirano rey Corbanto. Supuestamente, Felipe II desaprobó la dramatización entremesil del monarca. Pero de ser entremés o tragedia, lo cierto es que muchas circunstancias de las últimas dos décadas de la vida del monarca condicionaron un contexto que ayudó a la prohibición del 2 de mayo de 1598. Se comprende, entonces, la petición conciliadora de un Memorial de la villa de Madrid de ese mismo año en el que cautelosamente se aclara: "Allí se representa del rey justo

14 Juan de la Cueva, Ejemplar poético (1606) en Preceptiva..., p. 143. Cotéjense los siguientes versos de ANDrÉs Rey de ArTIEDA, Los amantes (1581), ibid., p. 67: "Si la materia dicen que no es alta./ pues para hablar de príncipes y reyes, / el hombre y reino a Los amantes falta,/ miren los que ordenaron esas leyes,/ que sacar al teatro un Minotauro,/ fue mandarnos tratar con semibueyes". Además de este pasaje para corroborar mi tesis de que el contubernio de los reyes con los bueyes ilustra la coyuntura entre lo trágico y lo cómico en el desarrollo del género, cotéjese el testimonio de Lope de Vega en el Arte nuevo, Juan Manuel Rozas, ed., Significado y' doctrina del "Arte nuevo" de Lope de Vega, SGEL, Madrid, 1976, p. 187: "Lo trágico y lo cómico mezclado, / y Terencio con Séneca, aunque sea/ como otro Minotauro de Pasife,/ harán grave una parte, otra ridicula..."(El subrayado es mío). Esta perspectiva coyuntural se aclara cuando se pondera la calidad real de Pasife y se la compara con la dignidad de algunas reinas y princesas dramatizadas contra quienes protestan los moralistas.

15 Juan de la Cueva, loc. cit.

16 Agustin de Rojas, Loa de la comedia (1693), en Preceptiva..., p. 125.

17 Anthony Watson, Juan de la Cueva and the Portuguese succession, Tamesis, London, 1971, pp. 118-150, y 205-206; Alfredo Hermenegil.do, La tragedia del renacimiento español, Planeta, Barcelona, 1973, pp. 308-315 y 362-363. 
el fin dichoso" ${ }^{18}$. Uno también sospecha que un autor trágico, como Argensola, se curaba en salud en ese mismo año de 1598 en otro Memorial cuando acusaba la representación de una boda del rey de Aragón "contra la dignidad de su persona; y á la Serenísima reina, su mujer, liviandades que en persona de mucha menor calidad fueran reprensibles" ". Sin embargo, uno recuerda la calidad y las liviandades de aquella difícil mujer, Alejandra, con cuyo nombre Argensola tituló su más famosa tragedia, ambientada en el contexto de las tiranías de su marido, el rey Acoreo. Junto al Príncipe Tirano y al Tirano rey Corbanto, la Alejandra de Argensola completa la trilogía trágica más conocida del peligroso período fillipino. La cautela de Argensola con su asunto merece el reconocimiento retórico de ser estudiada como una sutil Captatio Benevolentiae. Así, la loa expresa: "Pensais que estais en tiempo de Filipo,/ segundo Rey invicto desde nombre?/ y estais ( $;$ ai desdichados de vosotros!)/ . . . en la grande Ciudad llamada Mefis/ en donde reina y vive un Rey tirano..." ${ }^{20}$ Finalmente, en esta misma loa Argensola escuda su peligroso asunto detrás de los preceptos clásicos del decoro: "Estas tocas sangrientas, y corona/ y la lucida espada de dos cortes,/ os descubre mi nombre, que es Tragedia/ nascida de pecados (de los) Reyes..." En la edición de Margarete Newels que copio se lee: "Tragedia/nascida de pecados (de los) Reyes", mientras que otras ediciones del siglo xvill leen: "nacida de desgracias de los príncipes" 22 . Pienso, no obstante, que el cotejo cuidadoso de los manuscritos según la edición que copio, favorece la lectura que responsabiliza a los propios reyes por sus tragedias.

En a mbas lecturas, sin embargo, se sostiene el deslinde clásico entre los altos y los bajos personajes de Aristóteles y de sus comentaristas con que la tragedia discriminaba la jerarquía de su patetismo. Este deslinde fue confirmado en España por Carvallo y por Pellicer de Tovar $^{23}$, entre tantos otros que se resistían a las nuevas modalidades de

18 Memorial impreso dirigido al rey D. Felipe II. . (1598), en Bibliografia de las controversias, p. 422. En fecha del levantamiento de otra prohibición (1649) un Discurso apologético a nónimo razona de forma muy parecida. Véase ibid., p. 238.

19 Memorial sobre la representación de comedias... (1598), ibid., pp. 67-68.

20 Lupercio Leonardo de Argensola, "Loa", en Tragedia llamada Alexandra, apud Margarete Newels, Los géneros dramáticos en las poéticas del siglo de oro, Tamesis, London, 1974, pp. 162-163.

21 Ibid., p. 161.

22 Lupercio Leonardo de Argensola, "Loa", citada en Preceptiva..., p. 67, y en Juan José López de Sedano, Parnaso español, Madrid, 1772, t.6, pp. 421-424.

${ }^{23}$ El conocido precepto undécimo de José Pellicer de Tovar, Idea de la comedia de Castilla (1635), Preceptiva..., p. 269: “... y sólo se llama comedia la que consta de caso que acontece ent re particulares donde no hay prïncipe absoluto" (subrayado mío) sorprende; sobre todo en esta fecha que coincide con la muerte de Lope, cuando la conculcación de este precepto ya era la norma aceptada. Para una interesante interpretación social sobre los prejuicios del decoro "estamental" del Cisne de Apolo (1602) de Carvallo, véase José Antonio Maravall, La cultura del barroco, Ariel, Barcelona, 
la comedia. Destacadamente, se resistían a la convivencia del monarca con los modos y con los personajes alegres. Posiblemente, entonces, Argensola no hacía más que recoger un tópico de las preceptivas que, a lo mejor, paliaría la desaprobación del monarca.

Algunos pocos años después - ya difunto el monarca - Lope de Vega remite expresamente al disgusto de Felipe II, y nos da las razones que supuestamente lo motivaron: "o fuese el ver que al arte contradice,/ o cme la autoridad real no debe/ andar fingida entre la humilde plebe" ${ }^{24}$.

Claramente, Lope no respetó estas razones en su propia producción; y sus mismos defensores obviaron su conculcación de los preceptos. Caramuel, por ejemplo, atenuó expresamente la desaprobación de Felipe $11^{25}$, mientras que Agustín de Rojas francamente admitiría que en España, o bien se representaban los ejemplos ilustres de los linajes, o bien: "los vicios de algún príncipe,/ las crueldades o bajezas" ${ }^{26}$ con el propósito de que hubiera enmienda. El monarca que precedió esta edición de la Loa de la comedia de 1603 fue, precisamente, Felipe II.

A todo esto, Lope permaneció impenitente antes y después de sus pronunciamientos en el Arte nuevo. Me permito recordar a este propósito dos comedias gemelas en las que se evidencia el pertinaz desenfado del poeta. Me refiero a Los pleitos de Ingalaterra, que es anterior a 1604, y a su doble, La corona de Hungría, cuya redacción es bastante posterior; posiblemente de 1623. Esta última de hecho calca el argumento de la primera. En resumen: un monarca que se aproxima peligrosamente al comportamiento de un tirano, como en muchas otras comedias de Lope $^{27}$, cree una falsa acusación en contra de la

1975, p. 278; y para una interpretación abarcadora sobre las actitudes moralistas, véase Antonio Garcia Berrio, Intolerancia del poder y protesta popular en el Siglo de Oro. Los debates sobre la licitud moral del teatro, Universidad de Málaga, Málaga, 1978.

24 Lope de Vega, Arte nuevo, en Rozas, p. 186.

25 Juan Caramuel., Primus Calamus (1668), en Preceptiva..., p. 314 "His autem non ostantibus auderem dicere, non de omni Philipum comoedia: sed de ludicra agere... et apud nos Comoediae seriae nihil habent quod Regiam Majestatem deceat..."

26 Agustin de Rojas, Loa de la comedia (1603), en Preceptiva..., p. 122. El precepto octavo de Pellicer, ibid., p. 268, es un testimonio diametralmente opuesto: "Porque hay sucesos en las historias y casos en la invención incapaces de la publicidad en el teatro como son tiranías, sediciones de príncipes y vasallos..." La actitud del propio Lope puede cotejarse en su Dedicatoria a El serafin humano, apud Tномаs E. CASE, Las dedicatorias de partes $X I I I-X X$ de Lope de Vega, Estudios de Hispanófila, Chapel Hill-Valencia, 1975, p. 222: “. . porque las demás de las comedias, así de reyes como de otras personas graves, no se deben censurar con el rigor de historias donde la verdad es su objeto, sino a la traza de aquellos antiguos cuentos de Castilla que comienzan: Érase un Rey' y' una Reina; pues si no fuera de esta suerte, no lo pudieran sufrir los que lo son, y lo escuchan, y así se ven cada día representar sus vidas con cuanto para adornarlas fue gusto de los poetas".

${ }_{27}$ La mayor parte de las monografías que conozco sobre este tema suelen recons- 
virtud de la reina quien se ve obligada a ocultarse entre unos labradores estando ella a punto de parir dos gemelos herederos al trono. Años después (en las últimas escenas del segundo acto) también el rey se ve obligado a ocultarse en el monte después de una humillante derrota, y alli se ena mora de una labradora que le socorre sin saber que se trata de su infamada esposa. Sólo recojo una escena en la que Belardo responde a unos soldados que buscaban al rey después de su derrota. La temprana versión de Los pleitos de Ingalaterra es la más jugosa: Belardo: "Parece que por el rey/ del cielo nos preguntáis”./ Soldado: “_Porqué?"/ Belardo: "Porque le buscáis/ entre una muía y un buey"28. La irónica alusión al pesebre navideño no le acredita a este monarca dignidad real alguna, sino todo lo contrario. También la respuesta de Fineo en La corona, quien recomienda socarronamente a los soldados que busquen al rey con un villancico de la Nochebuena ${ }^{29}$, señala que aquella búsqueda estaba ridiculamente fuera del lugar y del contexto apropiado.

El desenfado de Lope en esta escena (que se mantiene invariable desde antes de 1604 hasta, posiblemente, 1623), retaría las advertencias del polémico maestro Pedro González de Sepúlveda recogidas por Cascales en las Cartas filológicas: "porque donde hacer sujeto de risa las acciones de un príncipe no sería decoro; burlarle a él ha de causar alborotos y escándalos y muertes; todo lo cual es puramente trágico" 30 .

Claro está, ni Lope, ni el vulgo, ni muchos de sus doctos estusiastas admitieron estas peligrosas consecuencias, como tampoco admitían los rigores de los preceptistas. Solía aducirse en la defensa de Lope el antecedente de la polémica italiana entre Guarini y Denores sobre la poesía tragicómica del Pastor fido; pero sobre todo, solía bastar la precedencia del Anfitrión de Plauto que se venía aduciendo en España

truir un ideario político a partir de citas ocasionales. Este es el caso de las tesis inéditas de V. Whitehouse (Harvard, 1929), E.J. Schuster (Minnesota, 1950), P. Rovner (Maryland, 1958), P. R. Frick (Georgia, 1972), E.M. Friesman (Yale, 1977). Los estudios recientes de Frances Exum, The metamorphosis of Lope de Vega's King Pedro, Playor, Madrid, 1974, y RiChard A. Youno, La figura del rey y la institución real en la comedia lopesca, Porrúa, Madrid, 1979, llegan a conclusiones particularizadas que sólo aplican a algunas comedias. Todavía resultan muy valiosas las sugerencias de OTis H. Green, "La dignidad real en la literatura del Siglo de Oro: notículas de un estudioso", $R F E, 48$ (1965), 231-250. Falta todavía un estudio sistemático y abarcador sobre el tema de la monarquía en el teatro de Lope de Vega.

${ }^{28}$ Los pleitos de Ingalaterra, AcadN, VIII, 518b. La aprobación de Pedro Vargas Machuca del I de enero de 1634 a La corona de Hungria, apud RiCHARD W. TYLER, ed., A critical edition of Lope de Vega's "La corona de Hungría", Estudios de Hispanófila, Chapel-Hill-Valencia, 1972, p. 158, en la que se asegura que la comedia "está bien escrita, y guardando el decoro a los personajes reales que introduce", tampoco nos ayuda a aclarar la naturaleza precisa de lo que Lope entendía por decoro en situaciones semejantes.

29 La corona de Hungria, AcadN, II, $47 \mathrm{~b}$.

${ }^{30}$ Francisco Cascales, Carias filológicas (1639), en Precepiiva..., p. 273. 
desde unos ambiguos pronunciamientos del Pinciano sobre este problema $^{31}$. Desde entonces se problematizaban las justificaciones de los doctos para la convivencia escénica de los personajes reales con los lacayos. Dicho de otra manera, la sanción por muchos cultos apologistas de Lope tan reconocidos como el abad de Rute o Cascales, a pesar de sus mutuas discrepancias, delata una fundamental coyuntura en la historia del desarrollo del género; a saber: la justificación teórica de una controvertible práctica que ya había sido aprobada por el uso y la costumbre. Pero esta sanción imponía algunas condiciones, siendo la más importante la propiedad del lenguaje, como repiten algunos entusiastas de Lope. Mártir Rizo (1623), Caramuel (1668) y Alcázar $(1690)^{32}$ repiten los señalamientos del propio Lope quien expresa en el Arte nuevo: "Si hablare el rey, imite cuanto pueda/ la gravedad real..." ${ }^{33}$ El rey no puede admitir chocarrería alguna en su estilo. Pero, cómo apaciguar a un Antonio López de Vega para quien la comedia "hace sentir, obrar y hablar los reyes como los ínfimos del pueblo, y los ínfímos del pueblo tal vez como los reyes" ${ }^{34}$, o cómo rebatir los resabios que recoge Cristóbal Suárez de Figueroa en El pasajero según los cuales la comedia consta "de cierta miscelánea donde se halla de todo. Graceja el lacayo con el señor, teniendo por donaire la desverguienza" ${ }^{35}$.

Lope mismo no podría replicar a estos señalamientos sin ser luego reprochado. Un enemigo declarado, Francisco Pérez de Amaya, pudo acusarle: "Al fin, las de Vmd., como lo confiesa, son comedias sin arte donde se han visto... tantos lacayos friáticos que departen con los

31 Véase Newels, pp. 140-152, para una visıón de conjunto. A propósito de la tragicomedia y de su afinidad con las comedias trabeata y togata expresa un personaje de Alonso López Pinciano, Filosofía antigua poética (1596), en Preceptiva..., p. 99: "...que faltan burlas muchas y palabras de donaire... por guardar el decoro a los dioses, reyes y personas principales, a las cuales es desconveniente la práctica de engendrar risa". Para los pronunciamientos en torno a la introducción de dioses y reyes, de acuerdo con el prólogo del Anfitrión de Plauto, pueden cotejarse los textos de Pinciano, de Cáscales y de Alcázar en Preceptiva. . ., pp. 98, 273 y 332, respectivamente. Para CASCales, ver además pp. 199-200. La defensa fundamental de Francisco Fernández de Cordoba (Abad de Rute) a la tragicomedia y a la comedia nueva en la Didascalia multiplex (1615), apud NEwELs, pp. 178-179, no es tan sutil en distinciones como el distingo de Cascales en las Tablaspoéticas (1617), Preceptiva..., p. 197 entre la "tragedia doble" y la "comedia doble" "[que] lleva algunos príncipes y personas ilustres, juntamente con las humildes". El Anfitrión pertenecería a esta última clasificación. Una y otra distinción dependen del desenlace feliz de la primera a pesar de su asunto trágico, y de la mezcla de personajes graves y humildes en la segunda a pesar de su asunto cómico.

32 Los textos de Rizo, Caramuel y Alcázar pueden cotejarse en Preceptiva, pp. 234,315 , y 334, respectivamente.

33 Lope de VEGa, Arte nuevo, en Rozas, p. 190.

34 Antonio López de VeGa, Heráclito y Demócrito de nuestro siglo (1641), en Preceptiva..., p. 275.

35 Cristóbal Suárez de Figueroa, El pasajero (1617), ibid., p. 189. 
Reyes, ya echando pullas, ya trayendo lugares de escritura" ${ }^{36}$; y esto era muy cierto cuando el mismo Lope advertía en el Arte nuevo que "no traya escritura" 37 .

A propósito de las Sagradas Escrituras recomendaba entusiasmadamente el Teólogo de los anónimos Diálogos de las comedias que las narraciones bíblicas atesoran las intrigas más apropiadas para tramas del tipo que nos ocupa: "Aquí sí que hay altibajos de fortuna, en que pastores o pastoras suben a reyes y reinas... ¿Dónde Lope o lobo [Lupus] carnicero de las almas... llegó a ingeniar o inventar ... a aventuras y valentías como las de David?" ${ }^{38}$

Si hay algo que no se le puede reprochar a Lope es una falta de inventiva para allegar pastores a la corte lo mismo que cortesanos a la aldea. Basta recordar algunos ejemplos conocidos. De nuevo, otra escurridiza infanta de León disfrazada de labradora se enamora y se casa con el hijo de Tello de Meneses, el Viejo, un campesino rancio y sin disfraz, a quien el rey llamaba "pariente" ". No obstante, en la segunda parte de Los Tellos de Meneses, un noble resentido le echa en cara al rey que su hermana estaba casada con un labrador: "Que ayer iba tras los bueyes, / aunque haya ejemplos tan llanos/de griegos y de romanos/ que hubo labradores reyes,/ León no ha de permitir/ que salgan de una montaña/ para gobernar a España" ${ }^{40}$. Sin embargo, esto fue, justamente, lo que caracterizó al ejemplo davídico del rey Bamba; y en frase de un personaje de la comedia del Capellán de la Virgen a propósito de este paradigma monárquico-campesino: "Verdad es que algunos reyes,/ como fruto, el campo ha dado,/ y del azadón/ al cetro real llegaron" 41 .

De acuerdo con semejante posibilidad ascensional del azadón al cetro, uno podría suscribir la hipótesis histórica de Pierre Chaunu sobre un Siglo de Oro en el que todavía persistiría el legado medieval de una dialéctica entre el hombre y el suelo. Se trataría, en frase de Chaunu, del "legado de la frontera" que se proyectaría todavía hacia el

36 Este fragmento de Pérez de Amaya del Examen crítico de la canción que hizo Lope de Vega a la venida del Duque de Osuna lo tomo de la edición de Juana de José Prades, ed., Elarte nuevo de hacer comedias en este tiempo, C.S.I.C., Madrid, 1971, p. 167.

Lope de VEGa, Arte nuevo, en Rozas, p. 189.

${ }_{38}$ Diálogos de las comedias, en Bibliografía de las controversias, pp. 224-225.

39 Los Tellos de Meneses, Primera parte, Acad, VII, 325a.

Los Tellos de Meneses, Segunda parte, Acad, VII, 348b. Compárese Los donaires de Matico, AcadN, IV, 699a: "Pero no es grande misterio/ que de un bajo captiverio,/ de guardar cabras y bueyes,/ contemplo romanos reyes/ a Justino y a Valerio". También: Mas valeis vos, Amona, que la corte toda, AcadN, VII, 404a: "Cuantos poderosos reyes/por la fortuna vivieron/a tal tiempo, que siguieron/con el arado los bueyes".

${ }^{41}$ El capellán de la Virgen, Acad, IV, $408 \mathrm{~b}$. 
sur con el desplazamiento territorial de la trashumancia ${ }^{42}$. La trashumancia perpetuaría la movediza frontera abriéndose paso desde León, por un lado, y Logroño por el otro, hasta Córdoba y Sevilla, atravesando toda la Extremadura y la Mancha. En resumen, esta abarcadora geografía ganadera proyectaría —en frase de Fernand Braudella "larga duración" de una sociedad y de una economía de base que venía delimitada oficialmente por la ganadería (y por el servicio de montazgo de la Mesta) a partir del siglo xilI. Si bien el avance secular de las cabras arrinconó el cultivo y cercó a los bueyes en las dehesas boyales en el siglo xvi, tanto las cabras como los bueyes convivieron en la geografía imaginaria de una tradición telúrica que conmemoraban los poetas. Es decir, si bien las cabras verdaderas que se desplazaron por las cañadas desafinaron con el bucolismo imaginario de las églogas, de las soledades y de las arcadias, al menos los bueyes de las comedias de Lope de Vega remiten a una realidad terrera que nos aproxima a la soltura con que Lope desatiende los preceptos del decoro: se trataría de su ambientación en un legado de pertenencia a la tradición de los campos. Por ejemplo, las referencias villanescas que tipifican este legado permiten algunas aberraciones campesinas como las de Juan Labrador: "Daré al Rey mi hacienda,/ hasta la oveja y el buey;/ más no he de ver al Rey/ mientras desto no se ofenda". A lo que el rey responde: "Y yo lo tengo de ver/ si tiene mayor poder/ que la corona el arado"43.

Esta disyuntiva simbólica entre el arado y la corona se neutraliza con el ejemplo ascensional del rey Bamba quien ta mbién profesó una aberración semejante a la de Juan Labrador: “Ténganse allá los reyes/ su reino poderoso,/ que yo con mis dos bueyes/ me hallo más ufano/ que si fuera señor del suelo hispano" ${ }^{44}$.

A pesar de esta profesión de felicidad agrícola, recordemos que una visión angélica del Papa señalaría a Bamba al trono, justamente con el acompañamiento distintivo de sus dos bueyes por los que unos mensajeros habrían de reconocerle como el designado para la monarquía. Según Menéndez Pelayo, la fuente de Lope para el legendario incidente del reconocimiento bovino del rey fue el Valerio de las historias escolásticas de España donde se lee: "Los mensajeros fueron repartidos por muchas partes, é uno dellos yendo cerca de un lugar que es en Portugal, que ha nombre Ircana la Vieja, oyeron decir de un cassar una voz de una mujer que decía: Bamba, dexad los bueves y venid a comer" ${ }^{45}$.

42 Pifrre Chaunu, La España de Carlos V, trad. de E. Riambau Saurí, Península, Barcelona, 1976, t.1 pp. 59-122.

${ }^{43}$ El villano en su rincón, Acad, XV, $281 \mathrm{a}$, respectivamente.

44 Comedia de Bamba, Acad, Vll, 5lb. Compárese Los jueces de Castilla, Acad, VIl, 382a: "Mejor que tu cetro el Rey/tomo el timón, cargo el pecho,/ rompiendo el duro barbecho/ altardo paso del buey".

45 Marcelino Menendez Pelayo, "Observaciones preliminares", Acad, VIl, xix; 
Ante testimonios como éste, uno desatiende los escrúpulos por el decoro y los escándalos que provocaban las infantas de León y las chocarrerías de los lacayos con los reyes. Aunque a mí me divierte muchísimo el apelativo de doña Sancha a su marido a la hora del almuerzo, pienso que la fuerza ilocutiva y que el contexto de esta espontánea invitación a comer localizan al monarca en el legado de la tierra junto al reclamo de la honra del linaje de los labradores que particularizó a muchas comedias de Lope a partir de $1605^{46}$. Posiblemente, este mismo legado propició el intercambio escénico de los coturnos con los zuecos en función de la fïgura del rey. En testimonio de Sancho Panza a la duquesa en la Segunda Parte del Quijote: "que de entre los bueyes, arados y coyundas sacaron al labrad or Wamba para ser rey de España" ${ }^{47}$. Lope, por lo que uno infiere del texto, dramatizó este asunto con gran unción y devoción en septiembre de 1598; con alusiones al "fuerte Felipe Segundo" 48 (quien murió en ese mismo mes de septiembre); pero todavía no estoy seguro si Lope desafiaba o se acomodaba a los memoriales y a las prohibiciones de aquel comprometedor año. Posiblemente sólo poetizaba un legado telúrico que le permitió expresar en una de las justas poéticas de San Isidro: "Los bueyes viendo la aurora,/ por Isidro preguntaban,/ que en aquella edad hablaban/ y también hablan ahora ..."49 De nuevo, ante testimonios como éste, uno podría desatender los escrúpulos por el decoro y por la verosimilitud; y asombrarse - no por el habla de los bueyessino por el desenfado con que Lope poetizaba el legado de su tradición.

Eduardo Forastieri-Braschi

Universidad de Puerto Rico.

J.W. SAGE,. "The context of comedy: Lope de Vega's El perro del hortelano and related plays", en Studies in Spanish literature of the Golden Age presented to Edward M. Wilson, R.O. Jones, ed., p. 250, señala que la Comedia de Bamba, lo mismo que el Valerio de Diego Rodríguez de Almella, delatan el fenómeno de la movilidad y del ascenso social junto al "isidrismo" geórgico que canonizaba al labrador San Isidro en el entorno del 1585. El titulo cuarto del Valerio en el que aparece la historia de Bamba está dedicado a "Aquellos que nacidos de bajo lugar fueron hechos claros y nobles..."

${ }_{46}$ Véase Salomon, op. cit., y Eduardo Forastiert-Braschi, Aproximación estructural al teatro de Lope de Vega, Hispanova, Madrid-Nueva York-San Juan, 1976, pp. 78-84; Américo Castro, De la edad conflictiva, 3a ed., Taurus, Madrid, 1972, pp. 312 y 222 , entre otras.

47 Miguel de Cervantes, Don Quijote, ed. cit., pp. 784-785.

48 Comedia de Bamba, Acad, VII, 69a.

${ }^{49}$ Justa poética celebrada con motivo de la canonización de San Isidro en 1619. Cito de acuerdo con Carlos Vossler, Introducción a la literatura española del Siglo de Oro, 3a, ed., Espasa-Calpe Mexicana, México, 1961, p. 68. 